\title{
Update on idiopathic interstitial pneumonias
}

\author{
Jay H. Ryu ${ }^{1}$ \\ Teng Moua ${ }^{1}$ \\ Felicia Montero-Arias ${ }^{2}$ \\ Eunhee S. $\mathbf{Y i}^{3}$ \\ ${ }^{1}$ Division of Pulmonary and Critical Care Medicine, \\ Mayo Clinic, Rochester, MN, USA \\ 2 Division of Pulmonology, Department of Medicine, \\ Hospital Mexico, San José, Costa Rica \\ ${ }^{3}$ Department of Anatomic Pathology, Mayo Clinic, \\ Rochester, MN, USA
}

\author{
Address for correspondence: \\ Jay H. Ryu, MD \\ Division of Pulmonary and Critical Care Medicine \\ Gonda 18 South, Mayo Clinic, 200 First St. SW \\ Rochester, MN 55905 - USA \\ Phone: 507-284-5398 \\ Fax: 507-266-4372 \\ E-mail: ryu.jay@mayo.edu
}

\section{Summary}

The idiopathic interstitial pneumonias (IIPs) comprise a major portion of diffuse infiltrative (interstitial) lung diseases. The classification of IIPs was initially conceived 4 decades ago and has undergone revisions over the intervening years with the most recent version published in 2013. Current classification distinguishes "major" forms of IIPs (idiopathic pulmonary fibrosis, idiopathic nonspecific interstitial pneumonia, respiratory-bronchiolitis-interstitial lung disease, desquamative interstitial pneumonia, cryptogenic organizing pneumonia, and acute interstitial pneumonia) from "rare" forms (idiopathic lymphoid interstitial pneumonia, idiopathic pleuroparenchymal fibroelastosis). In addition, the category of "unclassifiable" IIP is introduced in recognition of IIP cases that remain difficult to classify even with the current scheme. This review describes the historical background for IIPs, current perspectives, and summarizes the clinical-pathologic entities included in the current classification scheme.

KEY WORDS: idiopathic interstitial pneumonia, idiopathic pulmonary fibrosis, nonspecific interstitial pneumonia, interstitial lung disease, respiratory bronchiolitis, desquamative interstitial pneumonia, organizing pneumonia, acute interstitial pneumonia, lymphoid interstitial pneumonia, pleuroparenchymal fibroelastosis.

\author{
Introduction
}

Interstitial lung diseases (ILDs) comprise a heterogeneous spectrum of diffuse infiltrative lung diseases that give rise to respiratory symptoms, pulmonary infiltrates, and impaired gas exchange. Potential causes of ILD are numerous while for some patients no cause can be identified. A substantial portion of these latter patients have idiopathic interstitial pneumonias (IIPs), most commonly idiopathic pulmonary fibrosis (IPF) which histopathologically manifests usual interstitial pneumonia (UIP) pattern.

The concept of IIPs dates back to mid-1970s and has undergone several revisions in the intervening years $(1-4)$. The most recent iteration of this concept was formulated by an international panel of experts and investigators and published in 2013 (4). This review will highlight the clinically relevant aspects of IIPs as currently classified.

\section{Historical perspective}

Averill Liebow initially articulated the concept of IIPs in 1975 (Table 1) (1). The term was used to describe several histopathologic entities that share the feature of diffuse parenchymal infiltration with a tendency for fibrosis. This initial classification of IIPs included UIP desquamative interstitial pneumonia (DIP), bronchiolitis obliterans with interstitial pneumonia, lymphoid interstitial pneumonia (LIP), and giant cell interstitial pneumonia. In the following years the cause of giant cell interstitial pneumonia was identified to be heavy metal exposure and thus not "idiopathic". In addition, three forms of IIP became recognized, namely, respiratory bronchiolitis-associated interstitial lung disease (RBILD) (5), nonspecific interstitial pneumonia (NSIP) (6), and acute interstitial pneumonia (AIP) (7). In 2002, a panel of experts representing the American Thoracic Society and the European Respiratory Society published the first consensus statement on IIPS (3) which
These histopathologic patterns of interstitial pneumonias do not, in and of themselves, constitute a specific disease entity which requires integration of clinical and radiologic findings. was followed by an updated version earlier this year (Table 2) (4).

Terminology used in IIPs can be confusing for clinicians. It is important to keep in mind that some of the terms refer to histopathologic patterns while others connote specific disease entities. For example, UIP is 


\section{J.H. Ryu et al.}

Table 1 -Prior IIPs classifications.

\begin{tabular}{l|l|l}
\hline Liebow, $\mathbf{1 9 7 5}$ & Katzenstein, 1998 & ATS/ERS, 2002 \\
\hline Usual interstitial pneumonia & Usual interstitial pneumonia & $\begin{array}{l}\text { Idiopathic pulmonary fibrosis (usual } \\
\text { interstitial pneumonia) }\end{array}$ \\
\hline Desquamative interstitial pneumonia & $\begin{array}{l}\text { Desquamative interstitial pneumonia / } \\
\text { Respiratory bronchiolitis interstitial } \\
\text { lung disease }\end{array}$ & Desquamative interstitial pneumonia \\
\hline $\begin{array}{l}\text { Bronchiolitis obliterans with } \\
\text { interstitial pneumonia }\end{array}$ & Nonspecific interstitial pneumonia & $\begin{array}{l}\text { Respiratory bronchiolitis-interstitial } \\
\text { lung disease }\end{array}$ \\
\hline Lymphoid interstitial pneumonia & Acute interstitial pneumonia & Nonspecific interstitial pneumonia \\
\hline Giant cell interstitial pneumonia & & Acute interstitial pneumonia \\
\hline & & Lymphoid interstitial pneumonia \\
\hline
\end{tabular}

Table 2 - ATS/ERS 2013 Classification of idiopathic interstitial pneumonias.

\begin{tabular}{l}
\hline Major idiopathic interstitial pneumonias \\
Idiopathic pulmonary fibrosis \\
Idiopathic nonspecific interstitial pneumonia \\
Respiratory bronchiolitis-interstitial lung disease \\
Desquamative interstitial pneumonia \\
Cryptogenic organizing pneumonia \\
Acute interstitial pneumonia \\
Rare idiopathic interstitial pneumonias \\
Idiopathic lymphoid interstitial pneumonia \\
Idiopathic pleuroparenchymal fibroelastosis \\
Unclassifiable idiopathic interstitial pneumonias \\
\hline
\end{tabular}

a histopathologic pattern underlying the diagnosis IPF but can also be seen in other diseases such as druginduced lung diseases, connective tissue diseases, asbestosis and chronic hypersensitivity pneumonitis. Thus, an underlying cause can be identified in some patients with UIP pattern. Similar concepts hold true for other histopathologic patterns of interstitial pneumonia such as NSIP and diffuse alveolar damage (underlying histopathologic pattern for AIP) as will be explained later in this review. These histopathologic patterns of interstitial pneumonias do not, in and of themselves, constitute a specific disease entity which requires integration of clinical and radiologic findings.

\section{3 update on IIPs}

As already noted, an international panel of experts published an update on the classification of IIPs in 2013 (4). The current classification separates "major" forms of IIPs from "rare" forms to which is added idiopathic pleuroparenchymal fibroelastosis (PPFE). In addition, it is recognized that some cases of IIP remain difficult to classify even with the current scheme and are designated as "unclassifiable" IIP. Although most investigators acknowledge the relationship between smoking with RB-ILD and DIP ("smoking-related ILDs"), these two entities are retained in the 2013 classification. In the remainder of this review key aspects of each IIP are highlighted.

\section{Idiopathic Pulmonary Fibrosis (IPF)}

The concept of IPF remains as defined in the 2011 ATS/ERS consensus statement on diagnosis and management of IPF (8). IPF remains defined as a progressive ILD of unknown cause characterized by UIP pattern on lung biopsy or high-resolution computed tomography (HRCT). It is important to note that the demonstration of UIP pattern alone is not sufficient to make the diagnosis of IPF in the absence of appropriate clinical context. For example, histopathologic pattern of UIP can be encountered in patients with chronic hypersensitivity pneumonitis. In such patients atypical HRCT features (extensive ground-glass opacities or mosaic pattern due to air-trapping) can be a tipoff to the correct diagnosis (Figure 1). This example demonstrates the concept of clinico-radiologic-pathologic correlation required in diagnosing IIPs since histopathologic patterns in these disorders have varying degrees of specificity as to the underlying etiology. UIP pattern can be diagnosed by HRCT in the presence of several key features (8). These imaging features include reticular opacities and honeycombing that have subpleural and
IPF remains defined as a progressive ILD of unknown cause characterized by UIP pattern on lung biopsy or highresolution computed tomography (HRCT). 


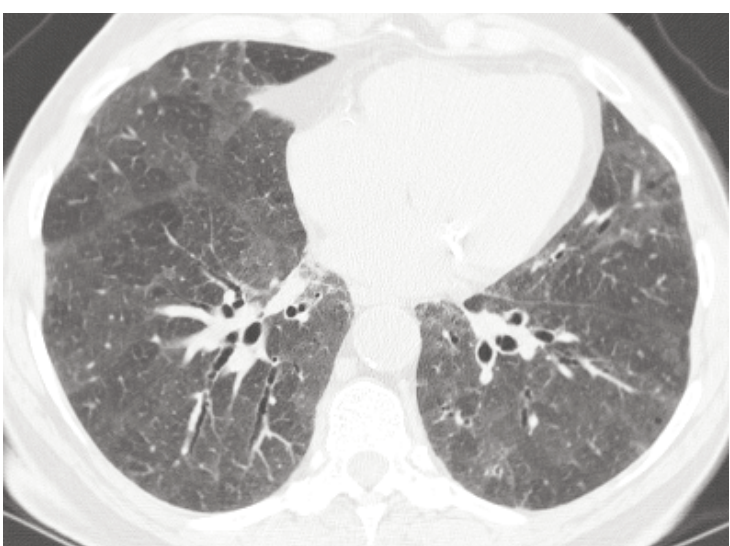

Figure 1 - High-resolution chest CT of a 75-year-old woman, nonsmoker, whose surgical lung biopsy showed a usual interstitial pneumonia (UIP) pattern. CT findings include patchy ground-glass opacities with a background of mosaic pattern and absence of subpleural honeycombing. Expiratory imaging confirmed patchy areas of air-trapping. Serologic testing revealed positivity to avian antigens, likely related to her bird feeders in the back yard. She improved with avoidance of additional exposure and prednisone treatment consistent with the diagnosis of chronic hypersensitivity pneumonitis.

basal predominance in the absence of features that are inconsistent with UIP pattern such as extensive ground-glass opacities, micronodules, or diffuse mosaic attenuation. If these characteristic imaging features are not present, a surgical lung biopsy may be needed to confirm the presence of UIP pattern.

The histologic pattern of UIP consists of several components including architectural distortion with dense fibrosis including honeycombing, fibroblast foci, temporal and geographic heterogeneity, and subpleural distribution $(3,8)$. Histopathologic pattern of UIP is difficult to diagnose by bronchoscopic biopsy which generally does not provide adequate amount of lung tissue to verify pattern diagnosis. However, recent studies suggest that bronchoscopic biopsy, particularly cryobiopsy, yields larger lung specimens with better preserved architecture which may avert the need for surgical lung biopsy in a substantial portion of patients with undiagnosed ILD (9-12)

Management options for patients with IPF remain limited. Pirfenidone has been approved for the treatment of IPF in Japan, Europe, and Canada, but not in the US $(8,13,14)$. Pulmonary rehabilitation measures are underused in this population and deserve additional consideration by clinicians caring for these patients (15, 16). Multiple pharmacologic agents including tyrosine kinase inhibitors (17) are undergoing clinical trials and may allow expansion of pharmacotherapeutic options for this disease (18).

\section{Idiopathic nonspecific interstitial pneumonia}

Nonspecific interstitial pneumonia is a histopathologic pattern characterized by varying degrees of chronic in- terstitial inflammation and interstitial fibrosis $(3,6,19)$. In contrast to UIP, overall lung architecture is generally preserved with absence of conspicuous temporal heterogeneity (including fibroblast foci) or honeycombing that characterize UIP pattern. Some investigators subdivide this histopathologic entity into cellular, mixed and fibrotic patterns depending on the predominant feature $(6,20)$. NSIP was initially described by Katzenstein et al. (6) in 1994 and these authors noted a heterogeneous spectrum of causes and underlying diseases that can be associated with this histopathologic pattern. These associations included connective tissue diseases, hypersensitivity pneumonitis, drug-induced lung disease, infections, immunodeficiency disorders, resolving acute lung injury, and many others.

On HRCT, NSIP is characterized by bilateral groundglass and reticular opacities that are predominantly peripheral and in the lower lungs. Traction bronchiectasis can be seen but subpleural honeycombing is generally absent. Although the presence of these features may allow the presumptive diagnosis of NSIP pattern in some clinical contexts, e.g., patients with connective tissue diseases, confirmation by surgical lung biopsy may be needed in other situations to distinguish NSIP from other ILDs with similar HRCT features such as chronic hypersensitivity pneumonitis, RB-ILD, DIP, organizing pneumonia, and eosinophilic pneumonias. Also, it is not uncommon that cases with radiologic pattern of NSIP prove to be UIP on histologic examination of lung biopsy; microscopic honeycomb changes appreciated in the lung biopsy might not be apparent on CT scan, which presumably leads to the radiologic interpretation as NSIP pattern in such cases.

In the absence of an identifiable cause or associated disease, the presence of NSIP pattern confers a diagnosis of idiopathic NSIP which is associated with a better response to therapy (typically corticosteroids) and prognosis compared to IPF $(19,21)$. Thus, distinguishing NSIP from UIP has treatment and prognostic implications.

In recent years, several reports have emerged suggesting the presence of evolving CTD in a substantial portion of patients diagnosed with idiopathic NSIP (22, 23). Such patients can be identified by the presence of autoimmune serologic markers such as antinuclear autoantibodies or anti-cyclic citrullinated peptide autoantibodies. Terms such as "undifferentiated CTD", "lungdominant CTD", and "autoimmune featured ILD" have been used to refer to such patients $(22,24,25)$. Some of these patients will eventually manifest overt clinical features diagnostic of a specific CTD $(23,25)$.

Treatment of idiopathic NSIP usually involves corticosteroids and other immunosuppressive agents, particularly azathioprine and mycophenolate mofetil, which is moderately effective in stabilizing or improving the lung 
disease and associated respiratory impairment (19, $21,26)$.

\section{Respiratory bronchiolitis-interstitial lung disease}

Respiratory bronchiolitis (RB) is a very common histopathologic finding in current or prior smokers and is characterized by the presence of pigmented macrophages in the respiratory bronchioles and peribronchiolar alveolar spaces $(3,27,28)$. Some patients with RB manifest evidence of ILD such as parenchymal opacities on HRCT or abnormalities on pulmonary function assessment. These latter subjects are said to have RB-associated ILD (RB-ILD) which can also be seen in some individuals exposed to solder fumes, diesel smoke and fiberglass dust (5, 29, 30).

Clinical presentation of pa-

In recent years, the trend has been to diagnose RB-ILD without confirmation by surgical lung biopsy when typical HRCT features are seen in smokers or ex-smokers with a substantial smoking history.

tients with RB-ILD may include respiratory symptoms such as cough and exertional shortness of breath while others are asymptomatic (5, 30-32). Most patients diagnosed with RBILD are between the ages of 30 and 60 years (30-32). Pulmonary function testing will typically reveal mild to moderate physiologic impairment with restrictive or obstructive pattern $(30,32)$.

Main findings on HRCT include patchy ground-glass opacities, ill-defined centrilobular nodules, and bronchial wall thickening $(33,34)$. Honeycombing and traction bronchiectasis are not seen. HRCT findings are not specific for RB-ILD, often overlapping with NSIP, DIP, and hypersensitivity pneumonitis.

For a definitive diagnosis, surgical lung biopsy is generally needed since bronchoscopic biopsy has a relatively low yield in this disorder. However, in recent years, the trend has been to diagnose RB-ILD without confirmation by surgical lung biopsy when typical HRCT features (Figure 2) are seen in smokers or exsmokers with a substantial smoking history. Some caution needs to be exercised in this regard since adenocarcinomas of the lung can also present with ground-glass opacities.

Main mode of treatment for RB-ILD is smoking cessation which usually leads to improvement or stability (5, 29-32, 35). The role of corticosteroid therapy remains limited to those with progressive disease or moderate to severe functional impairment. Prognosis is generally favorable for most patients especially for those who are able to quit smoking. However, there have been occasional reports of progressive RB-ILD resulting in death (32).

\section{Desquamative interstitial pneumonia}

Desquamative interstitial pneumonia (DIP) has several features similar to RB-ILD including a strong associa-

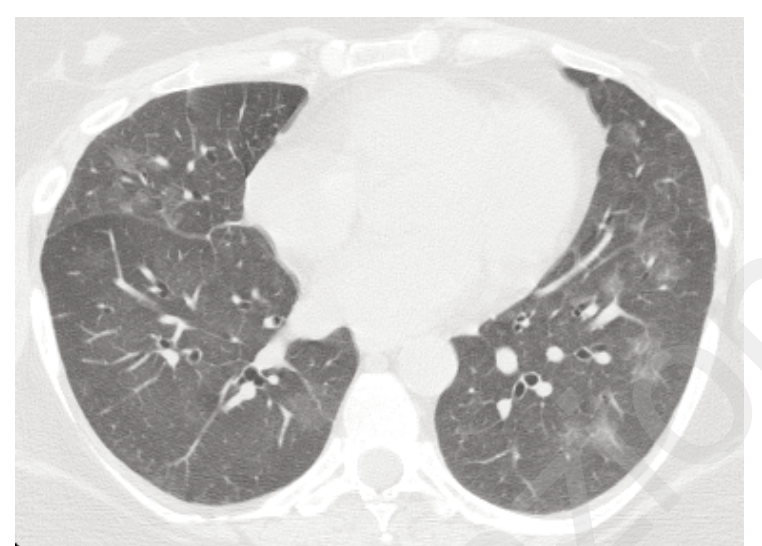

Figure 2 - High-resolution chest CT of a 51-year-old woman, active smoker, with respiratory bronchiolitis-associated interstitial lung disease (RB-ILD) demonstrating patchy groundglass opacities bilaterally. Surgical lung biopsy revealed marked respiratory bronchiolitis.

tion with smoking $(30,35)$. As with RB-ILD, DIP is characterized histopathologically by the accumulation of pigmented macrophages which is more diffuse and evenly dispersed within alveolar spaces compared to the bronchiolocentric distribution seen in RB-ILD (3, 36). Alveolar septae are mild to moderately thickened by interstitial inflammation and fibrosis. Dense fibrosis including honeycombing is absent.

Most patients diagnosed with DIP are between the ages of 30 and 60 years and 60 to $90 \%$ of the patients have a smoking history $(30,35,37)$. Less commonly DIP pattern can be seen in patients with druginduced lung disease, conIn the presence of typical clinical and radiological features, bronchoscopic biopsy demonstrating predominantly pigmented macrophages may be diagnostic for DIP. nective tissue disease, and en-

vironmental exposures (36-38). Typical presentation includes dyspnea and cough of insidious onset. Various patterns of pulmonary function abnormalities may be encountered in patients with $\operatorname{DIP}(30,31)$.

On HRCT, the predominant finding is ground-glass opacities that are bilateral and more extensive than those seen in RB-ILD $(33,34)$. In some patients, reticular opacities, emphysema, and cysts may also be present.

Confirming the diagnosis of DIP usually requires a surgical lung biopsy. In the presence of typical clinical and radiologic features, bronchoscopic biopsy demonstrating predominantly pigmented macrophages may suffice for diagnosis.

As with RB-ILD, smoking cessation is fundamental for those patients with DIP when it is associated with smoking. Smoking cessation can lead to improvement while continued smoking portends a worse prognosis $(30,37)$. Corticosteroids are commonly used but response is not uniform and approximately one-fourth of 
treated patients may exhibit worsening of lung disease (30). The role of cytotoxic and other immunomodulating therapies remain unclear. Mortality associated with DIP is higher compared to RB-ILD $(30,31)$.

\section{Cryptogenic organizing pneumonia}

Organizing pneumonia (OP) is a rather nonspecific histopathologic pattern of lung injury characterized by If bronchoscopic
biopsy is nondiagno-
stic, a surgical lung
biopsy may be nee-
ded to distinguish
COP from other dis-
ease with similar cli-
nico-radiologic featu-
res. polypoid intraluminal plugs of granulation tissue within alveolar ducts and spaces along with adjacent bronchioles (3, 39). Lung parenchyma tends to be involved in a patchy fashion while underlying lung architecture is generally preserved. While some authors have argued for excluding OP from the classification of IIPs based on this predominantly intraluminal rather than interstitial nature of this lesion (2), it is retained in the 2013 ATS/ERS classification of IIPS. OP pattern can be associated with a wide spectrum of causes and underlying diseases including infections, connective tissue diseases, radiation injury, aspiration, drug toxicity, and inhalational injuries. In approximately one-half of patients with OP pattern no cause or underlying disease can be identified for the lung injury. Such patients are diagnosed with cryptogenic organizing pneumonia (COP) $(28,40)$. As seen in NSIP, some patients with COP will eventually manifest evidence of an evolving connective tissue disease.

Most patients diagnosed with COP are in their $6^{\text {th }}$ or $7^{\text {th }}$ decade of life $(28,40,41)$. Presenting manifestations usually include cough and dyspnea of subacute onset (few to several weeks) but systemic symptoms such as fever, malaise, anorexia, and weight loss are also commonly present. Occasionally, fulminant presentation similar to acute respiratory distress syndrome may be seen (42).

Chest radiography usually demonstrates bilateral patchy alveolar opacities that have ground-glass or consolidative character and peripheral distribution on HRCT $(41,43)$. CT appearance may be similar to that seen in chronic eosinophilic pneumonia. Pulmonary function testing usually demonstrates a restrictive pattern $(39,40)$.

The diagnosis of COP requires histopathologic demonstration of the OP pattern and exclusion of known causes or underlying diseases. Bronchoscopic lung biopsy may suffice if characteristic lesion is identified in the presence of compatible clinical and radiologic findings. If the latter features are inconsistent or the bronchoscopic biopsy is nondiagnostic, a surgical lung biopsy may be needed to distinguish COP from other lung disease with similar clinico-radiologic features including hypersensitivity pneumonitis, NSIP, chronic eosinophilic pneumonia, diffuse alveolar damage, adenocarcinoma, and lymphoma.

Spontaneous improvement of COP is unusual and most patients require corticosteroid therapy, usually initiated with oral prednisone $30-60 \mathrm{mg}$ per day (39, 40). Clinical improvement tends to be seen promptly, usually within several days. The duration of therapy varies depending on the initial response and whether relapse occurs but is typically in the range of 6 to 12 months (40). Although prognosis associated with COP is generally excellent, death from progressive lung disease may sometimes occur despite corticosteroid therapy. Cytotoxic agents such as azathioprine and cyclophosphamide have been employed for some patients with progressive COP despite corticosteroid therapy.

\section{Acute interstitial pneumonia}

In contrast to other forms of IIPs, AIP is a rapidly progressive form of interstitial pneumonia. Clinically and radiologically, AIP presents with features similar to acute respiratory distress syndrome and corresponds to the Hamman-Rich syndrome originally described more than 60 years ago $(44,45)$. The histopathologic features of AIP are those of organizing diffuse alveolar damage which include the presence of hyaline membranes, diffuse septal edema, type II pneumocyte hy-
The histopathologic features of AIP are those of organizing diffuse alveolar damage which include the presence of hyaline membranes, diffuse septal edema, type II pneumocyte hyperplasia, and interstitial fibroblast proliferation. broblast proliferation $(7,46)$. Overall appearance is temporally homogeneous.

AIP is encountered in patients of wide age range with a mean age of approximately 50 years (46-49). Clinical presentation is usually that of a rapidly progressive respiratory disorder over a course of days to weeks and commonly includes constitutional symptoms such as fever, chills, malaise, myalgias, and arthralgias. Hypoxemia is common at presentation.

Chest radiography reveals bilateral alveolar infiltrates that may be patchy initially but tends to become diffuse. HRCT findings include diffuse ground-glass opacities and consolidation with air bronchograms (43, $50,51)$. Reticular opacities and traction bronchiectasis become apparent in the later phases of AIP.

There is no treatment that has been proven to be effective in the treatment of AIP although high-dose corticosteroid therapy is commonly employed (46, 49). Most patients require mechanical ventilation in setting of respiratory failure. Mortality rate associated with AIP is approximately $50 \%(46,49)$.

\section{Idiopathic lymphoid interstitial pneumonia}

In the 2013 ATS/ERS classification of IIPS, lymphoid interstitial pneumonia (also called lymphocytic interstitial pneumonia) has been relegated to the category of 
"rare" IIPS. LIP is characterized histopathologically by diffuse infiltration of alveolar septae with T-lymphocytes, plasma cells, and histiocytes $(3,52,53)$. Over the past decade it has been recognized that idiopathic LIP is exceedingly rare. Cases diagnosed as LIP in earlier reports likely included what would now be clas-

sified as NSIP or lymphoma

Recent reports have questioned the association of cystic lung disease with LIP, particularly in patients with Sjögren syndrome in whom cystic disease has been associated with mucosa-associated lymphoid tissue (MALT) lymphoma and amyloidosis.

(based on currently available immunohistochemical and molecular techniques). LIP pattern can be seen in a wide spectrum of clinical contexts including immunodeficiencies, connective tissue diseases (particularly Sjögren's syndrome), druginduced lung disease, viral infections, and other systemic diseases. Those with LIP in whom no known cause or association is identified have idiopathic LIP.

Imaging findings reported with LIP have been diverse and includes ground-glass opacities, ill-defined centrilobular nodules, thickening of the bronchovascular bundles, and interlobular septal thickening. In addition, parenchymal cysts have been reported in the majority of patients with LIP and have been thought to result from peribronchiolar lymphocytic infiltration with airway obstruction and distal dilatation. However, recent reports have questioned the association of cystic lung disease with LIP, particularly in patients with Sjögren syndrome in whom cystic disease has been associated with mucosa-associated lymphoid tissue (MALT) lymphoma and amyloidosis (54).

Most patients with idiopathic LIP are treated with corticosteroid therapy and clinical stability or improvement is generally expected (55-57). Prognosis is favorable but deaths from progressive lung disease and cor pulmonale or complications related to immunosuppressive therapy can occur (55-57).

\section{Idiopathic pleuroparenchymal fibroelastosis}

A new entry into the classification of IIPs is idiopathic pleuroparenchymal fibroelastosis (PPFE), a rare but distinct clinicopathologic entity

Role of genetic predisposition and autoimmunity has been suggested in the pathogenesis of pleuropulmonary fibroelastosis. characterized histopathologically by fibrosis involving the pleura and subpleural lung parenchyma (intraalveolar fibrosis with septal elastosis), predominantly affecting the upper lobes. Familial cases and association with hematopoietic stem cell transplantation have been reported but most cases are idiopathic (58-61). Role of genetic predisposition and autoimmunity has been suggested in the pathogenesis of this disorder (61).

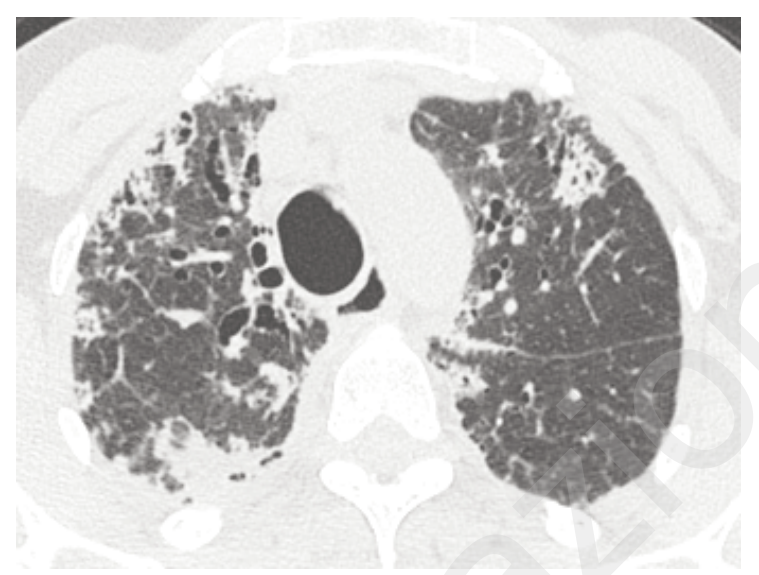

Figure 3 - High-resolution chest CT of the chest on a 60-yearold woman with idiopathic pleuroparenchymal fibroelastosis (confirmed by surgical lung biopsy) demonstrating pleural thickening, particularly in the right lung posteriorly, along with predominantly peripheral parenchymal fibrosis.

Patients with idiopathic PPFE are adults of wide age range presenting with shortness of breath and cough persistent over several months or years $(58,61)$. HRCT demonstrates pleural thickening and subpleural parenchymal fibrosis with upper lung predominance (Figure 3) (61, 62).

The majority of patients with idiopathic PPFE tend to progress despite treatment with corticosteroids and cytotoxic agents including azathioprine and cyclophosphamide $(58,60,61)$. In a recent report by Reddy et al. 5 of 10 patients died with the interval from diagnosis ranging from 4 months to 2 years (61).

\section{Unclassifiable idiopathic interstitial pneumonia}

Although the current classification accounts for most cases of IIPs encountered in clinical practice, it is acknowledged that there remain cases that do not easily fit into the entities described above. This dilemma may occur when overlapping or unusual histopathologic features are encountered or major discrepancies exist between clinical, radiologic and histopathologic findings. Some authors have included patients with undetermined ILD who are unable or unwilling to undergo a
Patients with undeunable or unwilling to undergo a surgical lung biopsy as well as those with insufficient lung biopsy sample may result having unclassifiable idiopathic interstitial pneumonia. termined ILD who are

surgical lung biopsy as well as those with insufficient lung biopsy sample (63). Using the latter inclusive criteria, $10 \%$ of patients with ILD are "unclassifiable" (63). These patients with unclassifiable ILD have a heterogeneous clinical course and overall similar survival to non-IPF ILD patients (63). 


\section{Conclusions}

Our understanding of IIPs is improving and, accordingly, the classification of these disorders continues to evolve to reflect the gained knowledge. IPF, the most common form of IIP, remains a lethal disorder with lim-

IPF, the most common form of IIP, remains a lethal disorder with limited management options.

of patients with IIPs.

\section{References}

1. Liebow A. Definition and classification of interstitial pneumonias in human pathology. Prog Respir Res. 1975;8:1-32.

2. Katzenstein AL, Myers JL. Idiopathic pulmonary fibrosis: clinical relevance of pathologic classification. Am J Respir Crit Care Med. 1998;157(4 Pt 1):130115.

3. American Thoracic S, European Respiratory S. American Thoracic Society/European Respiratory Society International Multidisciplinary Consensus Classification of the Idiopathic Interstitial Pneumonias. Am J Respir Crit Care Med. 2002;165(2):277304.

4. Travis WD, Costabel U, Hansell DM, King TE, Jr., Lynch DA, Nicholson AG, et al. An official american thoracic society/european respiratory society statement: update of the international multidisciplinary classification of the idiopathic interstitial pneumonias. Am J Respir Crit Care Med. 2013;188(6):73348.

5. Myers JL, Veal CF Jr, Shin MS, Katzenstein AL. Respiratory bronchiolitis causing interstitial lung disease. A clinicopathologic study of six cases. Am Rev Respir Dis. 1987;135(4):880-4.

6. Katzenstein AL, Fiorelli RF. Nonspecific interstitial pneumonia/fibrosis. Histologic features and clinical significance. Am J Surg Pathol. 1994;18(2):136-47.

7. Katzenstein AL, Myers JL, Mazur MT. Acute interstitial pneumonia. A clinicopathologic, ultrastructural, and cell kinetic study. Am J Surg Pathol. 1986;10(4): 256-67.

8. Raghu G, Collard HR, Egan JJ, Martinez FJ, Behr J, Brown KK, et al. An official ATS/ERS/JRS/ALAT statement: idiopathic pulmonary fibrosis: evidencebased guidelines for diagnosis and management. Am J Respir Crit Care Med. 2011;183(6):788-824.

9. Berbescu EA, Katzenstein A-LA, Snow JL, Zisman DA. Transbronchial Biopsy in Usual Interstitial Pneumonia. Chest. 2006;129(5):1126-31.

10. Tomassetti S, Cavazza A, Colby TV, Ryu JH, Nanni $\mathrm{O}$, Scarpi $\mathrm{E}$, et al. Transbronchial biopsy is useful in predicting UIP pattern. Respir Res. 2012;13:96.

11. Yarmus L, Akulian J, Gilbert C, Illei P, Shah P, Merlo $\mathrm{C}$, et al. Cryoprobe transbronchial lung biopsy in pa- tients after lung transplantation: a pilot safety study. Chest. 2013;143(3):621-6.

12. Griff S, Ammenwerth W, Schonfeld N, Bauer TT, Mairinger T, Blum T-G, et al. Morphometrical analysis of transbronchial cryobiopsies. Diagn Pathol. 2011;6:53.

13. Noble PW, Albera C, Bradford WZ, Costabel U, Glassberg MK, Kardatzke D, et al. Pirfenidone in patients with idiopathic pulmonary fibrosis (CAPACITY): two randomised trials. Lancet. 2011;377 (9779):1760-9.

14. Raghu G, Thickett DR. Pirfenidone for IPF: pro/con debate; the 'con' viewpoint. Thorax. 2013;68(7):6058.

15. Huppmann P, Sczepanski B, Boensch M, Winterkamp S, Schonheit-Kenn U, Neurohr C, et al. Effects of inpatient pulmonary rehabilitation in patients with interstitial lung disease. Eur Respir J. 2013;42 (2):444-53

16. Spruit MA, Singh SJ, Garvey C, Zuwallack R, Nici L, Rochester C, et al. An official american thoracic society/european respiratory society statement: key concepts and advances in pulmonary rehabilitation. Am J Respir Crit Care Med. 2013;188(8):e13-64.

17. Richeldi L, Costabel U, Selman M, Kim DS, Hansell DM, Nicholson AG, et al. Efficacy of a tyrosine kinase inhibitor in idiopathic pulmonary fibrosis. $\mathrm{N}$ Engl $\mathrm{J}$ Med. 2011;365(12):1079-87.

18. Richeldi L. Clinical trials of investigational agents for IPF: a review of a Cochrane report. Respir Res. 2013;14 Suppl 1:S4.

19. Travis WD, Hunninghake G, King TE Jr, Lynch DA, Colby TV, Galvin JR, et al. Idiopathic nonspecific interstitial pneumonia: report of an American Thoracic Society project. Am J Respir Crit Care Med. 2008;177(12):1338-47.

20. Travis WD, Matsui K, Moss J, Ferrans VJ. Idiopathic nonspecific interstitial pneumonia: prognostic significance of cellular and fibrosing patterns: survival comparison with usual interstitial pneumonia and desquamative interstitial pneumonia. Am J Surg Pathol. 2000;24(1):19-33.

21. Poletti V, Romagnoli M, Piciucchi S, Chilosi M. Current status of idiopathic nonspecific interstitial pneumonia. Semin Respir Crit Care Med. 2012;33(5):4409.

22. Kinder BW, Collard HR, Koth L, Daikh DI, Wolters PJ, Elicker B, et al. Idiopathic nonspecific interstitial pneumonia: lung manifestation of undifferentiated connective tissue disease? Am J Respir Crit Care Med. 2007;176(7):691-7.

23. Romagnoli M, Nannini C, Piciucchi S, Girelli F, Gurioli $\mathrm{C}$, Casoni $\mathrm{G}$, et al. Idiopathic nonspecific interstitial pneumonia: an interstitial lung disease associated with autoimmune disorders? Eur Respir J. 2011;38(2):384-91

24. Fischer A, West SG, Swigris JJ, Brown KK, du Bois RM. Connective tissue disease-associated interstitial lung disease: a call for clarification. Chest. 2010;138(2):251-6.

25. Vij R, Noth I, Strek ME. Autoimmune-featured interstitial lung disease: a distinct entity. Chest. 
2011;140(5):1292-9.

26. Kinder BW. Nonspecific interstitial pneumonia.Clin Chest Med. 2012;33(1):111-21.

27. Fraig M, Shreesha U, Savici D, Katzenstein AL. Respiratory bronchiolitis: a clinicopathologic study in current smokers, ex-smokers, and never-smokers. Am J Surg Pathol. 2002;26(5):647-53.

28. Ryu JH. Classification and approach to bronchiolar diseases. Curr Opin Pulm Med. 2006;12(2):145-51.

29. Moon J, du Bois RM, Colby TV, Hansell DM, Nicholson AG. Clinical significance of respiratory bronchiolitis on open lung biopsy and its relationship to smoking related interstitial lung disease. Thorax. 1999;54(11):1009-14.

30. Ryu JH, Myers JL, Capizzi SA, Douglas WW, Vassallo R, Decker PA. Desquamative interstitial pneumonia and respiratory bronchiolitis-associated interstitial lung disease. Chest. 2005;127(1):178-84.

31. Yousem SA, Colby TV, Gaensler EA. Respiratory bronchiolitis-associated interstitial lung disease and its relationship to desquamative interstitial pneumonia. Mayo Clin Proc. 1989;64(11):1373-80.

32. Portnoy J, Veraldi KL, Schwarz MI, Cool CD, CurranEverett D, Cherniack RM, et al. Respiratory bronchiolitis-interstitial lung disease: long-term outcome. Chest. 2007;131(3):664-71.

33. Heyneman LE, Ward S, Lynch DA, Remy-Jardin M, Johkoh T, Muller NL. Respiratory bronchiolitis, respiratory bronchiolitis-associated interstitial lung disease, and desquamative interstitial pneumonia: different entities or part of the spectrum of the same disease process? AJR. 1999;173(6):1617-22.

34. Desai SR, Ryan SM, Colby TV. Smoking-related interstitial lung diseases: histopathological and imaging perspectives. Clin Radiol. 2003;58(4):259-68.

35. Ryu JH, Colby TV, Hartman TE, Vassallo R. Smoking-related interstitial lung diseases: a concise review. Eur Respir J. 2001;17(1):122-32.

36. Tazelaar HD, Wright JL, Churg A. Desquamative interstitial pneumonia. Histopathology. 2011;58(4): 50916.

37. Godbert B, Wissler M-P, Vignaud J-M. Desquamative interstitial pneumonia: an analytic review with an emphasis on aetiology. Eur Respir Rev. 2013;22 (128):117-23.

38. Carrington $\mathrm{CB}$, Gaensler EA, Coutu RE, FitzGerald MX, Gupta RG. Natural history and treated course of usual and desquamative interstitial pneumonia. $\mathrm{N}$ Engl J Med. 1978;298(15):801-9.

39. Ryu JH, Myers JL, Swensen SJ. Bronchiolar disorders. Am J Respir Crit Care Med. 2003; 168(11): 1277-92.

40. Cordier JF. Cryptogenic organising pneumonia. Eur Respir J. 2006;28(2):422-46.

41. Drakopanagiotakis F, Paschalaki K, Abu-Hijleh M, Aswad B, Karagianidis N, Kastanakis E, et al. Cryptogenic and secondary organizing pneumonia: clinical presentation, radiographic findings, treatment response, and prognosis. Chest. 2011;139(4):893900.

42. Cohen AJ, King TE Jr, Downey GP. Rapidly progressive bronchiolitis obliterans with organizing pneu- monia. Am J Respir Crit Care Med. 1994;149 (6):1670-5.

43. Lynch DA, Travis WD, Muller NL, Galvin JR, Hansell DM, Grenier PA, et al. Idiopathic interstitial pneumonias: CT features. Radiology. 2005;236(1):10-21.

44. Hamman L, Rich AR. Fulminating Diffuse Interstitial Fibrosis of the Lungs. Trans Am Clin Climatol Assoc. 1935;51:154-63.

45. Olson J, Colby TV, Elliott CG. Hamman-Rich syndrome revisited. Mayo Clin Proc. 1990;65(12):153848.

46. Mukhopadhyay S, Parambil JG. Acute interstitial pneumonia (AIP): relationship to Hamman-Rich syndrome, diffuse alveolar damage (DAD), and acute respiratory distress syndrome (ARDS). Semin Respir Crit Care Med. 2012;33(5):476-85.

47. Vourlekis JS, Brown KK, Cool CD, Young DA, Cherniack RM, King TE, et al. Acute interstitial pneumonitis. Case series and review of the literature. Medicine. 2000;79(6):369-78.

48. Bonaccorsi A, Cancellieri A, Chilosi M, Trisolini R, Boaron M, Crimi N, et al. Acute interstitial pneumonia: report of a series. Eur Respir J. 2003;21(1):18791.

49. Parambil JG, Myers JL, Aubry M-C, Ryu JH. Causes and prognosis of diffuse alveolar damage diagnosed on surgical lung biopsy. Chest. 2007; 132(1):50-7.

50. Dixon S, Benamore R. The idiopathic interstitial pneumonias: understanding key radiological features. Clin Radiol. 2010;65(10):823-31.

51. Hansell DM. Acute interstitial pneumonia: clues from the white stuff. Am J Respir Crit Care Med. 2002; 165(11):1465-6.

52. Travis WD, Fox CH, Devaney KO, Weiss LM, O'Leary TJ, Ognibene FP, et al. Lymphoid pneumonitis in 50 adult patients infected with the human immunodeficiency virus: lymphocytic interstitial pneumonitis versus nonspecific interstitial pneumonitis. Human Pathol. 1992;23(5):529-41.

53. Travis WD, Galvin JR. Non-neoplastic pulmonary lymphoid lesions. Thorax. 2001;56(12):964-71.

54. Baqir M, Kluka EM, Aubry M-C, Hartman TE, Yi ES, Bauer PR, et al. Amyloid-associated cystic lung disease inprimary Sjogren's syndrome. Respir Med. 2013;107(4):616-21.

55. Swigris JJ, Berry GJ, Raffin TA, Kuschner WG. Lymphoid interstitial pneumonia: a narrative review. Chest. 2002;122(6):2150-64.

56. Cha SI, Fessler MB, Cool CD, Schwarz MI, Brown KK. Lymphoid interstitial pneumonia: clinical features, associations and prognosis. Eur Respir J. 2006;28(2):364-9.

57. Tian X, Yi ES, Ryu JH. Lymphocytic interstitial pneumonia and other benign lymphoid disorders. Semin Respir Crit Care Med. 2012;33(5):450-61.

58. Frankel SK, Cool CD, Lynch DA, Brown KK. Idiopathic pleuroparenchymal fibroelastosis: description of a novel clinicopathologic entity. Chest. 2004;126 (6):2007-13.

59. von der Thusen JH, Hansell DM, Tominaga M, Veys PA, Ashworth MT, Owens CM, et al. Pleuroparenchymal fibroelastosis in patients with pulmonary dis- 
ease secondary to bone marrow transplantation. Mod Pathol. 2011;24(12):1633-9.

60. Kusagaya H, Nakamura Y, Kono M, Kaida Y, Kuroishi $\mathrm{S}$, Enomoto $\mathrm{N}$, et al. Idiopathic pleuroparenchymal fibroelastosis: consideration of a clinicopathological entity in a series of Japanese patients. BMC Pulm Med. 2012;12:72.

61. Reddy TL, Tominaga M, Hansell DM, von der Thusen J, RassI D, Parfrey H, et al. Pleuroparenchymal fibroelastosis: a spectrum of histopathological and imag- ing phenotypes. Eur Respir J. 2012;40(2):377-85.

62. Piciucchi S, Tomassetti S, Casoni G, Sverzellati N, Carloni A, Dubini A, et al. High resolution CT and histological findings in idiopathic pleuroparenchymal fibroelastosis: features and differential diagnosis. Respir Res. 2011;12:111.

63. Ryerson CJ, Urbania TH, Richeldi L, Mooney JJ, Lee JS, Jones KD, et al. Prevalence and prognosis of unclassifiable interstitial lung disease. Eur Respir J. 2013;42(3):750-7. 